\title{
Are neighborhood bonding and bridging social capital protective against depressive mood in old age? a multilevel analysis in Japan
}

Hiroshi Murayama ${ }^{1,2 *}$, Yu Nofuji ${ }^{1}$, Eri Matsuo ${ }^{1}$, Mariko Nishi ${ }^{1}$, Yu Taniguchi ${ }^{1}$, Yoshinori Fujiwara $^{1}$, Shoji Shinkai ${ }^{1}$

1: Research Team for Social Participation and Community Health, Tokyo Metropolitan Institute of Gerontology, Tokyo, Japan

2: University of Michigan School of Public Health, Ann Arbor, MI, USA

*Corresponding author: Hiroshi Murayama, PhD, RN, PHN

Research Team for Social Participation and Community Health, Tokyo Metropolitan Institute of Gerontology, 35-2 Sakae-cho, Itabashi-ku, Tokyo 173-0015, Japan

Tel: +81-3-3964-3241 (ext. 4253)

Fax: +81-3-3579-4776;

e-mail: murayama@tmig.or.jp 


\section{ABSTRACT}

2 While the importance of distinguishing between bonding and bridging social capital is now 3 understood, evidence remains sparse on their contextual effects on health. We examined the associations of neighborhood bonding and bridging social capital with depressive mood among older Japanese. A questionnaire survey of all community residents aged 65 and older in the city of Yabu, Hyogo Prefecture, Japan was conducted in July and August 2012. Bonding and bridging social capital were assessed by evaluating individual homogeneous and heterogeneous social networks in relation to age, gender, and socioeconomic status. Individual responses in each neighborhood were aggregated to create an index of neighborhood-level bonding/bridging social capital. Odds ratios (ORs) and $95 \%$ confidence intervals (CIs) were calculated to evaluate the associations of such social capital with depressive mood using multilevel binomial logistic regression analysis. Of the 7,271 questionnaires distributed, 6,416 were analyzed (covering 152 administrative neighborhoods). Approximately $56.8 \%$ of respondents were women, and the mean age was $76.2 \pm 7.1$ years. Neighborhood-level bonding social capital was inversely associated with depressive mood $(\mathrm{OR}=0.84,95 \% \mathrm{CI}=0.75-0.94)$, but neighborhood-level bridging social capital was not. Gender-stratified analysis revealed that neighborhood-level bonding social capital was inversely associated with depressive mood in both genders $(\mathrm{OR}=0.83$, 95\% $\mathrm{CI}=0.72-0.96$ for $\mathrm{men} ; \quad \mathrm{OR}=0.85, \quad 95 \% \quad \mathrm{CI}=0.72-0.99$ for women), while neighborhood-level bridging social capital was positively associated with depressive mood in women $(\mathrm{OR}=1.15,95 \% \mathrm{CI}=1.00-1.34)$. There was also a significant interaction between individual- and neighborhood-level bonding social capital, indicating that people with a weaker homogeneous network and living in a neighborhood with weaker bonding social capital were more likely to have depressive mood. Our results suggest that neighborhood social capital does not necessarily benefit mental health in old age. These findings might stimulate further discussion on the relationship of bonding and bridging social capital with mental health. 
27 Keywords: bonding social capital; bridging social capital; contextual effect; neighborhood;

28 community-dwelling elderly; depressive mood; multilevel modeling; Japan 


\section{INTRODUCTION}

Social capital has been discussed in many academic fields. Putnam (1993) wrote that the term refers to "features of social organization, such as trust, norms and networks that can improve the efficacy of society by facilitating coordinated actions." The association between social capital and health has been examined in a number of papers in the public health arena, particularly in social epidemiology. Social capital has been conceptualized using different approaches (Kawachi, 2006). In public health research to date, the most common approach is to define it as a contextual resource (social cohesion definition).

Because social capital is an umbrella concept, subclassification of its aspects and dimensions may help clarify its effects on health. One approach distinguishes between two main components—bonding and bridging social capital (Putnam, 2000). Szreter and Woolcock (2004) stated that bonding social capital refers to aspects of "inward-looking" social networks that reinforce exclusive identities and group homogeneity in social characteristics; while bridging social capital refers to "outward-looking" social networks, which extend across different social and ethnic groups that do not necessarily share similar identities. The importance of differentiating between these types of social capital has recently been understood, and empirical studies have investigated their effects on health.

Most previous studies focused on the relationship of individual-level bonding/bridging social capital with health outcomes. Beaudoin (2009) found that stronger bonding and bridging social capital — defined based on the relationships of an individual with people of (dis)similar race/ethnicity — were both associated with better self-rated health, and that stronger bonding social capital was associated with reduced stress among general adults living in various parts of the United States. Mitchell and LaGory (2002) defined these types of social capital as strength of trust and ties with others whose race and education are (dis)similar to those of the respondent, and reported interesting associations with mental distress. In an impoverished U.S. community, stronger bridging social capital was associated with lower levels of mental distress, opposite to 
greater bonding social capital.

Designs of earlier studies on the associations of bonding/bridging social capital with health can be improved in at least two respects. First, very few focused on their contextual effects on health with a multilevel analysis. Kim, Subramanian, and Kawachi (2006) focused on the contextual effects on health of bonding and bridging social capital, defined as above by Szreter and Woolcock (2004). They reported that, among U.S. adults, community-level bonding social capital (determined by examining the relationships of an individual with people of similar race/ethnicity, gender, and education) was associated with better self-rated health, while community-level bridging social capital was not. From China, Meng and Chen (2014) reported that county-level bridging trust was beneficial toward individuals' self-rated health in both urban and rural areas, and that particularly in urban areas, people who have high individual-level bonding trust and live in a county with a high level of bonding trust evaluated their health more favorably. Even some of the studies that focused on individual-level bonding/bridging social capital implicitly acknowledged the presence of their contextual effects (Anonymous, 2013; Poortinga, 2012). Anonymous (2013) reported that individual perception of neighborhood homogeneity (in relation to age, gender, and socioeconomic status [SES]) was inversely associated with poor self-rated health and depressive mood among older Japanese. As mentioned above, a great deal of public health research has treated social capital as a group-level attribute. Examination of the contextual effects of these types of social capital on health may yield new insights into the design of policies and community interventions to promote health.

A second shortcoming of previous studies on bonding/bridging social capital is that they were mainly limited to data derived from Western countries. To date, Meng and Chen (2014) has been the only work focusing on the contextual effect of these forms of social capital on health from Asian populations, but there are no Japan-based studies. In Japan-viewed as a relatively collectivist society on the whole, with strong group ties-residents within a 
community feel comfortable under systems of mutual assurance and monitoring (Nakane, 1970; Yamagishi, Cook, \& Watabe, 1998; Yamagishi \& Yamagishi, 1994). In view of the differences in background between the populations of Western countries and Japan, it is important to examine the effects of bonding/bridging social capital on health in Japan.

Previous studies on Western countries have defined bonding and bridging social capital based on relationships with racially or ethnically (dis)similar people (Beaudoin, 2009; Kim et al., 2006; Poortinga, 2012). However, because Japan has low racial/ethnic diversity, we considered this definition inappropriate for Japan. Moreover, the meaning of social relationships might differ between Japan and Western societies; it was reported that Japanese elderly had fewer social ties compared with U.S. elderly (Sugisawa, Okabayashi, Nakaya, Fukaya, \& Shibata, 1998). For example, in terms of age, because Japanese elderly tend to possess fewer networks with different generations as they age (Cabinet Office, 2009), connections with different age groups might have unique value as age advances. Regarding gender, because predominance of men over women remains rooted in Japanese society, particularly in rural areas and in old age (Gerteis, 2009), older people are apt to maintain relations with those of the same gender. Connections with the opposite gender can therefore be seen as heterogeneous relationships. Socioeconomic disparity has increasingly widened in Japan (Ministry of Health, Labour and Welfare, 2013), so ties among people with different socioeconomic positions may have a distinct meaning. Taken together, focus on the (dis)similarity of relationships with regard to age, gender, and SES seems more significant than race/ethnicity when considering bonding and bridging social capital in a study targeting Japan.

Another feature of this study is that we considered depressive mood in old age because elderly adults often experience changes in factors such as social functions, social relations, and physical condition (Müller-Spahn \& Hock, 1994; Rowe \& Kahn, 1997). In fact, scale-based studies of depression symptoms showed the rate of depression increases with age (Luppa et al., 2012; Stordal et al., 2001). Moreover, depression is a risk factor for functional decline in later 
life (Stuck et al., 1999). In Japan, the importance of preventing depression in old age has been recognized because measuring of depression has been considered a good indicator for developing public health policy, particularly for long-term care prevention (Ministry of Health, Labour and Welfare, 2012). Some studies have reported a preventive contextual effect of social capital on depressive mood (Aslund, Starrin, \& Nilsson, 2010; Kouvonen et al., 2008; Tomita \& Burns, 2013), but the contextual associations of bonding and bridging social capital with depressive mood have yet to be studied.

Given these considerations, to have valuable public health implications and develop population-/community-based approaches, a study exploring the contextual relationship with depressive mood among Japanese elderly appears of critical importance. In this study, we examined the relationship between neighborhood bonding and bridging social capital and depressive mood (i.e., contextual association) among older Japanese. Gender difference in the association between bonding/bridging social capital and health has also been found in some Japanese studies (Iwase et al., 2012; Kishimoto et al., 2013). For example, bridging social capital was found to have a stronger association with self-rated health in women than in men (Iwase et al., 2012). Moreover, some other studies reported a significant interaction between individual- and contextual-level social capital on health outcomes such as self-rated health (Han, Kim, \& Lee, 2012; Meng \& Chen, 2014). This approach suggests that all individuals in areas or groups in a specific context (e.g., neighborhoods, workplaces, schools) are equally exposed, but that health effects may vary among individuals. However, there is little evidence of the interaction between these two different levels and depressive mood. Thus, this study has two purposes in addition to the main one: identify gender difference in the contextual associations of bonding and bridging social capital with depressive mood, and test the interaction between individual- and neighborhood-level bonding and bridging social capital on depressive mood.

We offer the following hypotheses. For older Japanese, (1) neighborhood bonding and bridging social capital are associated with depressive mood, and the net of individual social 
capital; (2) the associations of these two types of neighborhood social capital with depressive mood are different; (3) the association between neighborhood bonding/bridging social capital and depressive mood is stronger and/or more likely to be more significant for women than men; and (4) the associations between neighborhood bonding/bridging social capital and depressive mood differ according to the form of individual social capital.

\section{METHODS}

\section{Study population}

We conducted a cross-sectional survey in July and August 2012. The target population was all community residents aged 65 and above in the city of Yabu in Hyogo Prefecture, Japan, who were not certified for long-term care levels 1-5. A questionnaire was mailed to 7,271 residents. The study protocol was approved by the Ethical Committee of Anonymous. All participants gave informed consent before their inclusion in the study.

Yabu is located in northern Hyogo and is $100 \mathrm{~km}$ northwest of Osaka and Kyoto. As of July 1, 2012, it had a population of 26,642 (12,787 male and 13,855 female), with population density of 63.0 people $/ \mathrm{km}^{2}$, and contains 161 administrative neighborhoods. The proportion of people aged 14 and younger was approximately $11.8 \%$. In contrast, that of people aged 65 and older was $32.6 \%$. The national average for the latter is $23.0 \%$. From a level of $21.6 \%$ in 1990 , this proportion is predicted to reach $40.9 \%$ by 2025 and $43.5 \%$ by 2040 (National Institute of Population and Social Security Research, 2014). From April 2011 through March 2012, the respective rates of inflow (moving to Yabu) and outflow (moving from Yabu) were $1.63 \%$ and $2.66 \%$ (vs. $4.21 \%$ and $4.20 \%$ nationally; Ministry of Internal Affairs and Communications, 2012). As a whole, Yabu can be said to be a representative rural area in Japan because of its rapidly aging population and low population density and fluidity. Anonymous (2014) gives further details on the participants and study area. 


\section{Measurements}

\section{Bonding/bridging social capital}

Based on previous studies (Harpham, Grant, \& Thomas, 2002; Kawachi, Subramanian, \& Kim, 2008; Poortinga, 2012; Szreter \& Woolcock, 2004), Anonymous (2013) developed a system of assessing bonding social capital using two factors and bridging social capital by a single factor. As mentioned in the introduction, we focused on the (dis)similarity of relationships with regard to age, gender, and SES. The items assess bonding and bridging social capital by investigating perceptions of homogeneity and heterogeneity in participant networks. Because perceived network homogeneity and heterogeneity are regarded as the strength of personal networks with others who have similar or dissimilar social characteristics, we assumed that homogeneous and heterogeneous networks were not opposing concepts. The concepts of bonding and bridging social capital were examined with the statements: "Do you agree that in your daily life you have networks with people who have similar social characteristics (age, gender, and SES) to you?" and "Do you agree that in your daily life you have networks with people who have dissimilar social characteristics to you?" (1=agree, $2=$ somewhat agree, $3=$ neither, 4=somewhat disagree, 5=disagree). We conducted a preliminary interview investigation on a sample of elderly residents of Yabu to verify the validity and reliability of these items in this study setting. Overall, the subjects had strong understanding of the items, so we used them in the survey. The responses for the two items were relatively normally distributed (Table 1).

Individuals were grouped within administrative neighborhoods. In addition to individual-level social capital, aggregate-level social capital was created in accordance with the neighborhood units by aggregating individual responses in each neighborhood. The proportions of people with a strong homogeneous/heterogeneous network (response categories 1 and 2) in neighborhoods were calculated for neighborhood-level bonding and bridging social capital. 


\section{Depressive mood}

Depressive mood was assessed using the Geriatric Depression Scale (GDS) short-form (Burke, Roccaforte, \& Wengel, 1991; Schreiner, Hayakawa, Morimoto, \& Kakuma, 2003), which was developed as a basic screening measure of depressive mood in older adults. Respondents answered dichotomized questions, and the answers were summed up (score range: 0-15). Cronbach's alpha was 0.85 . A cutoff point of $5 / 6$ was adopted, and a score of $\geq 6$ indicated depressive mood (Schreiner et al., 2003).

\section{Covariates}

Gender, age, marital status, educational attainment, annual household income, smoking, body mass index, comorbidities, functional capacity, and general trust were adjusted for in the analysis. The comorbidities of interest were hypertension, cardiovascular disease, cerebrovascular disease, hyperlipidemia, and diabetes mellitus. Functional capacity was composed of basic activities of daily living (BADL) and higher-order competence of independence. BADL was measured using five items (walking, eating, bathing, dressing, and toileting), and the score range was 0-5. Higher-order competence was measured using the Tokyo Metropolitan Institute of Gerontology Index of Competence (TMIG-IC), which consists of a 13-item index (score range: 0-13) (Koyano, Shibata, Nakazato, Haga, \& Suyama, 1991). A higher score indicated greater independence. For BADL, a score of 5 indicated complete independence.

Both individual- and neighborhood-level general trust was adjusted for as a cognitive aspect of social capital, because in this study bonding and bridging social capital reflected the presence of social structures and differential components of social capital (e.g., cognitive vs. structural) can influence difference in the association of social capital with depressive mood (Bassett \& Moore, 2013). The question used to evaluate trust was, "Generally speaking, can most people be trusted?" (1=agree, $2=$ somewhat agree, $3=$ neither, $4=$ somewhat disagree, 
$5=$ disagree). We dichotomized responses as strong (1 and 2) and weak (3-5). An index of neighborhood-level general trust was created in the same manner as the indices for bonding/bridging social capital. The proportions of people with strong general trust in neighborhoods were calculated.

\section{Neighborhood living environment}

Neighborhood living environment might affect social capital because people living in walkable, mixed-use neighborhoods were found to have high levels of social capital (Leyden, 2003). Thus, we asked questions on neighborhood living environment to identify neighborhood characteristics associated with strong bonding/bridging social capital. The questionnaire included items on three aspects of this environment: accessibility to facilities (ease of access to nonresidential facilities), safety, and landscape (neglect concerning presence of litter or graffiti). Responses were made on a five-point Likert scale (1=agree, $2=$ somewhat agree, $3=$ neither, 4=somewhat disagree, $5=$ disagree). As with social capital variables, the proportions of the three items were calculated by aggregating individual responses for categories 1 and 2 among the respondents in neighborhoods.

\section{Statistical analysis}

To examine the compositional (individual-level) and contextual (neighborhood-level) effects of bonding and bridging social capital on depressive mood, we conceptualized the analysis as a multilevel structure. We fitted the data using a multilevel binomial logistic regression model that included a random intercept to assess the likelihood of a GDS score of $\geq 6$ versus a score of $\leq 5$. Full maximum likelihood procedure was the estimation method. We conducted the analysis for the entire sample and by gender. Individual-level covariates, neighborhood-level population size, and neighborhood-level aging rate were adjusted for in all models. Because social capital at the neighborhood level was composed of aggregated 
individual responses, social capital at the individual level may be a confounding factor for the contextual effect of social capital on depressive mood (Oakes, 2004). Therefore, we added both individual- and neighborhood-level social capital in the model simultaneously. Individual-level indicators of social capital were centered on the neighborhood mean to overcome the problem of collinearity between individual-level and neighborhood-level variables. All neighborhood-level variables were centered on their grand mean. The results of the fixed effects are expressed as odds ratios (ORs) with 95\% confidence intervals (CIs). Statistical analysis was performed using IBM SPSS 20 and HLM 6.08.

\section{RESULTS}

Of the 7,271 questionnaires distributed, 6,652 were returned (91.5\% response rate). After excluding 186 from respondents who did not actually reside in the city or had been admitted to the hospital or lived in nursing facilities, 41 that were completely/almost blank, four with missing neighborhood labels, and five that identified neighborhoods with fewer than three respondents, we analyzed data from 6,416 respondents gathered in 152 neighborhoods with three or more respondents. The mean number of respondents in a neighborhood was 47.6 (ranging 3-185). The response rates varied by neighborhood between $67 \%$ and $100 \%$, but about $90 \%$ of the neighborhoods had a response rate of $80 \%$ or above. Among the 152 neighborhoods, 10 contained less than 10 respondents within the area.

Table 1 shows the characteristics of the respondents. Approximately $56.8 \%$ were women and the mean age was $76.2 \pm 7.1$ years. Regarding social capital, $48.6 \%$ had a strong homogeneous network and $17.7 \%$ had a strong heterogeneous network. About $39.9 \%$ had a score of $\geq 6$ on the GDS.

\section{<Insert Table 1 here>}

We calculated correlation coefficients among neighborhood social capital, neighborhood living environments, and neighborhood demographics (Table 2). 
Neighborhood-level bonding social capital was moderately correlated with neighborhood accessibility to facilities $(\mathrm{r}=0.27)$ and landscape $(\mathrm{r}=-0.21)$, and bridging social capital was correlated with neighborhood safety $(\mathrm{r}=-0.29)$ and landscape $(\mathrm{r}=0.31)$.

<Insert Table 2 here>

Table 3 shows associations of bonding and bridging social capital with depressive mood for the entire sample. Individual-level strong bonding social capital was significantly inversely associated with depressive mood (Models 1 and 3); but after adjusting for general trust in Model 4 this association remained significant only for the "strong" category $(\mathrm{OR}=0.68,95 \%$ $\mathrm{CI}=0.50-0.92)$. Regarding the association between individual-level bridging social capital and depressive mood, the category "neither" had lower ORs in Models 2-4 compared with that of "weak" (e.g., $\mathrm{OR}=0.77,95 \% \mathrm{CI}=0.63-0.95$ in Model 4), while OR in the category of "strong" did not significantly differ from that of "weak." Neighborhood-level bonding social capital was inversely associated with depressive mood, even after adjusting for bridging social capital and general trust in Model $4(\mathrm{OR}=0.84,95 \% \mathrm{CI}=0.75-0.94)$. In contrast, neighborhood-level bridging social capital was not associated with depressive mood.

<Insert Table 3 here>

In gender-stratified analysis (Table 4 for men and Table 5 for women), neighborhood-level bonding social capital had a significant inverse association with depressive mood in men and women (e.g., in Model 4, OR=0.83, 95\% CI=0.72-0.96 in men, and $\mathrm{OR}=0.85$, 95\% CI=0.72-0.99 in women). In contrast, neighborhood-level bridging social capital was significantly positively associated with depressive mood in women $(\mathrm{OR}=1.15,95 \%$ $\mathrm{CI}=1.00-1.34$ in Model 4) but not in men. We also found a significant interaction between bridging social capital and general trust at the neighborhood level in women only $(\mathrm{OR}=1.07$, 95\% CI=1.01-1.12; data not shown), indicating that women living in the neighborhood who had weaker bridging social capital and higher general trust were less likely to have depressive mood than women living in the other neighborhoods. The predicted probability of depressive mood for 
women living in the neighborhood with weak bridging social capital and strong general trust was $33.8 \%(95 \% \mathrm{CI}=32.5-35.1)$, while that for women in the other neighborhoods was $37.7 \%$ $(95 \% \mathrm{CI}=36.5-38.8)$.

<Insert Table 4 and 5 here>

Finally, we examined the effect of the interaction of individual-level and neighborhood-level social capital (i.e., bonding and bridging social capital and general trust) on depressive mood, by separately adding the interaction term into Model 4. There was a significant interaction between individual- and neighborhood-level bonding social capital on depressive mood in the entire sample (Model 5 in Table 3). In the neighborhood with weak bonding social capital, the predicted probability of depressive mood for those with weak bonding social capital was $50.5 \%(95 \% \mathrm{CI}=48.2-52.7)$, while that for those with strong bonding social capital was $32.8 \%(95 \% \mathrm{CI}=31.4-34.1)$. In the neighborhood with strong bonding social capital, it was $39.9 \%$ (95\% CI=32.2-47.6) for those with weak bonding social capital vs. $29.4 \%$ (95\% CI=26.7-32.0) for those with strong bonding social capital. These indicated that people who had a weaker homogeneous network and lived in a neighborhood with weaker bonding social capital were more likely to have depressive mood. Apart from this interaction, however, no significant interaction between individual- and neighborhood-level social capital was found.

\section{DISCUSSION}

This questionnaire-based study of older Japanese had a high response rate and is the first to examine the contextual associations of bonding and bridging social capital with depressive mood in older Japanese. Interestingly, we found that the two forms of social capital had contrasting associations with depressive mood. Overall, neighborhood-level bonding social capital was inversely associated with depressive mood in both genders, while neighborhood-level bridging social capital was positively associated with depressive mood among women. With a rapidly aging population and low population density and fluidity, Yabu 
is a representative rural area in Japan. Generally, rural areas in Japan tend to be more collectivist than urban areas (Yamazaki, 1990). In rural communities, individuals cooperate with groups because of the presence of a system of formal and informal mutual assurance (or lack of social uncertainty), monitoring and sanctioning derived from the stability of interpersonal and/or inter-organizational relations (Yamagishi et al., 1998; Yamagishi \& Yamagishi, 1994). Japanese societies, seen as collectivistic, therefore have many characteristics not observable in Western countries, which are usually regarded as having individualistic societies. Moreover, the definitions of bonding and bridging social capital in Western societies are often based on (dis)similarity in relation to race/ethnicity. However, in a society with greater racial/ethnic homogeneity, such as Japan, other aspects should be focused on. Although further examination is needed, this study, which focused on (dis)similarity in age, gender, and SES, could provide implications for what elements comprise bonding and bridging social capital in such a society. Neighborhood bonding social capital was found to be inversely associated with depressive mood among both men and women. Previous studies also reported or implied a beneficial effect of community bonding social capital on health (Kim et al., 2006; Anonymous, 2013; Poortinga, 2012). According to our definition of bonding social capital, in a neighborhood with stronger bonding social capital there would be dense networks among people with similar social backgrounds, such as networks among elderly adults, men, women, and people in the same area of business. Shared personal characteristics in the neighborhood elicit trust in others as well as social resemblance, which may foster development of a social support system and provide residents with a feeling of security (Kawachi \& Berkman, 2000). Moreover, dense homogeneous networks in neighborhoods might facilitate delivery of health interventions to specific groups, such as in improving information distribution in an area (Kawachi \& Berkman, 2000). Such networks might therefore improve the mental health of residents.

An alternative explanation for the inverse association between neighborhood bonding social capital and depressive mood highlights the role of neighborhood services and amenities, 
as in how Haines, Beggs, and Hurlbert (2011) reported the close linkage among neighborhood

342 (dis)advantage, social capital, and depressive symptoms. We found a moderate positive 343 correlation between neighborhood bonding social capital and accessibility to facilities. A stronger homogeneous network among those with similar sociodemographic characteristics in a neighborhood (i.e., gathering people of similar backgrounds in a neighborhood) could bring together people's opinions and result in more obvious and greater needs for certain services or amenities. The attempt to meet these resident needs could increase allocation and maintenance of such resources in a neighborhood. Such services and amenities would in turn positively influence the mental health of residents through giving them satisfaction and the ability to use such resources. Moreover, we found a significant interaction between individual- and neighborhood-level bonding social capital and depressive mood. This indicates a buffering effect of neighborhood bonding social capital on depressive mood in that stronger neighborhood bonding social capital partially offset the deleterious effect of possession of a weak homogeneous network on depressive mood. This implies that, for example, in a neighborhood with dense homogeneous networks, relative to those with weak bonding social capital, those with strong individual bonding social capital can more efficiently and effectively obtain useful and personally necessary information from rich sources of information in the area by using their personal homogeneous networks. This finding leads to a possible policy recommendation that it would be effective to strengthen neighborhood bonding social capital to prevent depressive mood particularly among those with a weak homogeneous network, who are thus more likely to have depressive mood.

In contrast, people living in neighborhoods with stronger bridging social capital were at higher risk of depressive mood, particularly in women. In such neighborhoods, there would be many broad networks among people with different sociodemographic characteristics. Our results showed that greater neighborhood bridging social capital was correlated with lower neighborhood safety and a poorer neighborhood landscape. Moreover, about $85 \%$ of our sample 
had lived in the city for over 40 years. Older people who have lived for a long time in a collectivist community with mutual assurance might have a negative opinion of neighborhoods in which people of varying sociodemographic backgrounds interact. Living in such neighborhoods might increase levels of unease and stress among residents. In particular, because the employment rate of women in Japan is much lower than that among men (Ministry of Internal Affairs and Communications, 2013), women are less likely than men to have experience in committing to active involvement in society outside the residential community (e.g., workplace). Therefore, women may feel more stress than men when living in neighborhoods with strong bridging social capital. Another possible explanation for this association is that, in the neighborhood in which the elderly are more likely to report having heterogeneous networks, these networks may have formed an inferior alternative to preferred social networks (e.g., family connections or support) that are unavailable. That is, the elderly are compelled to have heterogeneous networks because of the difficulty obtaining their preferred networks. Therefore, the circumstances of such residential neighborhoods might negatively relate to individual mental health, particularly among women. Putnam (2000) also argued that people in more diverse communities are less likely to trust their neighbors. We in fact found a significant interaction between bridging social capital and general trust at the neighborhood level among women, indicating that women living in the neighborhood who had weaker bridging social capital and higher general trust were less likely to have depressive mood. To further our level of understanding of the association between neighborhood-level bridging social capital and depressive mood, we need to closely investigate the actual condition of social networks in the neighborhood and examine the detailed relationship between bridging social capital (or neighborhood diversity), social trust, and people's mental health.

Regarding individual-level social capital, bonding social capital (homogeneous network) was inversely associated with depressive mood. Meanwhile, the association of bridging social capital (heterogeneous network) with depressive mood was different. People 
with a moderately heterogeneous network (indicated by a response of "neither") were unlikely to have depressive mood, and this trend of the association remained in the gender-stratified analysis, even though it did not reach statistical significance. Having a heterogeneous network is considered a benefit because people can receive new information and ideas through it (Granovetter, 1973). Some previous studies support the benefit of having heterogeneous ties on people's mental health (Mitchell \& LaGory, 2002; Anonymous, 2013). However, in a traditional Japanese collectivist community, strong ties within the group tend to prevent connections such as trust from developing beyond group boundaries (Yamagishi et al., 1998), suggesting that a strong heterogeneous network may not be preferred in such a community. This might offset the beneficial effect of having strong heterogeneous networks. This sense of tension might lead to a situation in which people who have a moderately (i.e., neither strong nor weak) heterogeneous network can live a more peaceful, less stressful life in a community than those with a strongly or weakly heterogeneous network. In a previous study that used the same measurements of bonding and bridging social capital among older adults in a Japanese community (Hatoyama, Saitama Prefecture), a stronger individual heterogeneous network was associated with less risk of depressive mood, while a homogeneous network was not (Anonymous, 2013). Hatoyama was developed as a commuter town for Tokyo (Anonymous, 2012). It is a typical suburban area and thus tends to be less collectivist than rural areas in Japan (Yamazaki, 1990). Therefore, the discrepancy in the associations reported in these two studies might be due to the background characteristics of the settings. Because members of a more collectivist culture provide mutual assurance in committed relations (Yamagishi \& Yamagishi, 1994), older people in such a community (e.g., Yabu) might be reassured when they have a strong homogeneous network. As a previous study reported on the effect of social capital on health varied by area characteristics (i.e., urban and rural) (Meng \& Chen, 2014), our findings also suggest that community characteristics can strongly influence the linkage between social capital and health.

There are still few studies on bonding and bridging social capital and depressive mood. 
One earlier study shows that social ties outside the neighborhood (i.e., a type of bridging social capital) were associated with better self-rated health because they indicate good access to a

421 greater diversity of resources (Moore et al., 2011). However, Bassett and Moore (2013) reported that people with social ties spanning both neighborhood and non-neighborhood locations (i.e., a type of bonding and bridging social capital) had greater likelihood of depressive symptoms compared with those with neighborhood ties only. This difference in associations may be due to fundamental differences in the selected outcome. The current study could contribute to better understanding of the specific linkage between bonding/bridging social capital and depressive mood.

This study has some limitations. First, further examination of the validity and reliability of the measurements for bonding and bridging social capital would be useful. We cannot rule out the possibility that these items are double-barreled and over-simplified. For example, we measured homogeneous and heterogeneous network in terms of sociodemographics including age, gender, and SES in a single item. The items have a strength in that bonding and bridging social capital can be captured easily. However, we cannot identify what kinds of homogeneity/heterogeneity the respondents' network had (i.e., age, gender, or SES). This study's findings should be carefully interpreted and more robust items concerning bonding and bridging social capital should be developed (e.g., using multiple items for them). We also need to ask some questions to examine whether age, gender, and SES are sufficient components of social characteristics in measuring bonding and bridging social capital. Marital status or family structure, because it has been increasingly changing in Japan, may be another sociodemographic component (Rindfuss, Choe, Bumpass, \& Tsuya, 2004). Second, the neighborhood-level variables were created by aggregating the individual responses of only the older people living in the neighborhood. Although the study response rate was high, the target population was limited to Yabu residents aged 65 and older. Thus, to develop contextual indicators that are more genuine and reflective of reality, young and middle-aged populations 
should be included. Moreover, we included all neighborhoods with three or more respondents in

446 the analysis in accordance with the process by Kouvonen et al. (2008). However, a larger

447 number of the respondents in a neighborhood unit might more powerfully reflect the actual conditions of the neighborhood. We undertook a sensitivity analysis by running the same multilevel modeling excluding neighborhoods with fewer than 10 respondents from the analysis, and obtained similar results as those reported in this study. Third, this was a cross-sectional study. A longitudinal study is necessary to confirm causal relationships and design an effective intervention. Fourth, the target community was small. Although the current study could provide unique findings on the linkage between neighborhood bonding and bridging social capital and depressive mood, care should be taken when generalizing these findings.

\section{CONCLUSIONS} and provide guidelines for policies on health promotion and community development. 
472 This study was supported by research grants from the Research Institute of Science and 473 Technology for Society (RISTEX), the Japan Science and Technology Agency, and the city of 474 Yabu.

475

476

477

\section{REFERENCES}

Aslund, C., Starrin, B., \& Nilsson, K. W. (2010). Social capital in relation to depression, musculoskeletal pain, and psychosomatic symptoms: a cross-sectional study of a large population-based cohort of Swedish adolescents. BMC Public Health, 10, 715.

482

Bassett, E., \& Moore, S. (2013). Social capital and depressive symptoms: the association of psychosocial and network dimensions of social capital with depressive symptoms in Montreal, Canada. Social Science \& Medicine, 86, 96-102.

Beaudoin, C. E. (2009). Bonding and bridging neighborliness: an individual-level study in the context of health. Social Science \& Medicine, 68(12), 2129-2136.

Burke, W. J., Roccaforte, W. H., \& Wengel, S. P. (1991). The short form of the Geriatric Depression Scale: a comparison with the 30-item form. Journal of Geriatric Psychiatry and Neurology, 4, 173-178.

Cabinet Office. (2009). Kouresha no chiikishakai heno sanka ni kansuru ishiki tyosa hokokusho 2008 [Survey report on social participation among the elderly 2008]. Tokyo: Cabinet Office.

Gerteis, C. (2009). Gender struggles: wage-earning women and male-dominated unions in postwar Japan. MA: Harvard University Press.

Granovetter, M. S. (1973). The strength of weak ties. American Journal of Sociology, 78, 1360-1380. 
Haines, V. A., Beggs, J. J., \& Hurlbert, J. S. (2011). Neighborhood disadvantage, network social capital, and depressive symptoms. Journal of Health and Social Behavior, 52, 58-73.

Han, S., Kim, H., \& Lee, H. S. (2012). A multilevel analysis of social capital and self-reported health: evidence from Seoul, South Korea. International Journal for Equity in Health $11,3$.

Harpham, T., Grant, E., \& Thomas, E. (2002). Measuring social capital within health surveys: key issues. Health Policy and Planning, 17, 106-111.

Iwase, T., Suzuki, E., Fujiwara, T., Takao, S., Doi, H., \& Kawachi, I. (2012). Do bonding and bridging social capital have differential effects on self-rated health? a community based study in Japan. Journal of Epidemiology \& Community Health, 66, 557-562.

Kawachi, I. (2006). Commentary: social capital and health: making the connections one step at a time. International Journal of Epidemiology, 35, 989-993.

Kawachi, I., \& Berkman, L. F. (2000). Social cohesion, social capital, and health. In L. F. Berkman \& I. Kawachi (Eds.), Social epidemiology (pp. 174-190). New York: Oxford University Press.

Kawachi, I., Subramanian, S. V., \& Kim, D. (2008). Social capital and health: a decade of progress and beyond. In I. Kawachi, S. V. Subramanian \& D. Kim (Eds.), Social capital and health (pp. 1-26). New York: Springer.

Kim, D., Subramanian, S. V., \& Kawachi, I. (2006). Bonding versus bridging social capital and their associations with self rated health: a multilevel analysis of 40 US communities. Journal of Epidemiology \& Community Health, 60, 116-122.

Kishimoto, Y., Suzuki, E., Iwase, T., Doi, H., \& Takao, S. (2013). Group involvement and self-rated health among the Japanese elderly: an examination of bonding and bridging social capital. BMC Public Health, 13, 1189.

Kouvonen, A., Oksanen, T., Vahtera, J., Stafford, M., Wilkinson, R., Schneider, J., et al. (2008). Low workplace social capital as a predictor of depression: the Finnish Public Sector 
Koyano, W., Shibata, H., Nakazato, K., Haga, H., \& Suyama, Y. (1991). Measurement of competence: reliability and validity of the TMIG Index of Competence. Archives of Gerontology and Geriatrics, 13, 103-116.

Leyden, K. M. (2003). Social capital and the built environment: the importance of walkable neighborhoods. American Journal of Public Health, 93, 1546-1551.

Luppa, M., Sikorski, C., Luck, T., Ehreke, L., Konnopka, A., Wiese, B., et al. (2012). Age- and gender-specific prevalence of depression in latest-life: systematic review and meta-analysis. Journal of Affective Disorders, 136, 212-221.

Meng, T., \& Chen, H. (2014). A multilevel analysis of social capital and self-rated health: evidence from China. Health \& Place, 27, 38-44.

Ministry of Health, Labour and Welfare. (2012). Manual for care prevention. Tokyo: Ministry of Health, Labour and Welfare.

Ministry of Health, Labour and Welfare. (2013). Survey on the redistribution of income 2011. Tokyo: Ministry of Health, Labour and Welfare.

Ministry of Internal Affairs and Communications. (2012). Report on internal migration in

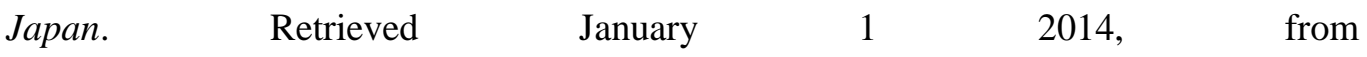
http://www.stat.go.jp/english/data/idou/index.htm

Ministry of Internal Affairs and Communications. (2013). Employment status survey 2012. Tokyo: Ministry of Internal Affairs and Communications.

Mitchell, C. U., \& LaGory, M. (2002). Social capital and mental distress in and impoverished community. City \& Community, 1, 199-222.

Moore, S., Bockenholt, U., Daniel, M., Frohlich, K., Kestens, Y., \& Richard, L. (2011). Social capital and core network ties: a validation study of individual-level social capital measures and their association with extra- and intra-neighborhood ties, and self-rated health. Health \& Place, 17, 536-544. 
Müller-spahn, F., \& Hock, C. (1994). Clinical presentation of depression in the elderly. Gerontology, 40, 10-14.

Anonymous (2013). Details omitted for double-blind reviewing.

Anonymous (2012). Details omitted for double-blind reviewing.

Anonymous (2014). Details omitted for double-blind reviewing.

Nakane, C. (1970). Japanese society. Los Angeles: University of California Press.

National Institute of Population and Social Security Research. (2014). Nihon no chiiki betsu shorai suike jinko: 2010-2040 [Regional population projections for Japan: 2010-2040]. Tokyo: Health and Welfare Statistics Association.

Oakes, J. M. (2004). The (mis)estimation of neighborhood effects: causal inference for a practicable social epidemiology. Social Science \& Medicine, 58, 1929-1952.

Poortinga, W. (2012). Community resilience and health: the role of bonding, bridging, and linking aspects of social capital. Health \& Place, 18, 286-295.

Putnam, R. D. (1993). Making democracy work: civic traditions in modern Italy. NJ: Princeton University Press.

Putnam, R. D. (2000). Bowling alone: the collapse and revival of American community. New York: Simon \& Schuster.

Rindfuss, R. R., Choe, M. K., Bumpass, L. L., \& Tsuya, N. O. (2004). Social networks and family change in Japan. American Sociological Review, 69, 838-861.

Rowe, J. W., \& Kahn, R. L. (1997). Successful aging. Gerontologist, 37, 433-440.

Schreiner, A. S., Hayakawa, H., Morimoto, T., \& Kakuma, T. (2003). Screening for late life depression: cut-off scores for the Geriatric Depression Scale and the Cornell Scale for Depression in Dementia among Japanese subjects. International Journal of Geriatric Psychiatry, 18, 498-505.

Stordal, E., Kruger, M. B., Dahl, N. H., Kruger, O., Mykletun, A., \& Dahl, A. A. (2001). Depression in relation to age and gender in the general population: the Nord-Trondelag 
Health Study (HUNT). Acta Psychiatrica Scandinavica, 104, 210-216.

Stuck, A. E., Walthert, J. M., Nikolaus, T., Bula, C. J., Hohmann, C., \& Beck, J. C. (1999). Risk factors for functional status decline in community-living elderly people: a systematic literature review. Social Science \& Medicine, 48, 445-469.

Sugisawa, H., Okabayashi, H., Nakaya, Y., Fukaya, T., \& Shibata, H. (1998). Kouresha no seikatsu to Kenko ni kansuru nichibe hikaku: syakai kanke ni tyakumoku shite [Comparison in daily living and health of the elderly between Japan and the United Status: focusing on social relationships]. Journal of Health and Welfare Statistics, 45, 23-29.

Szreter, S., \& Woolcock, M. (2004). Health by association? social capital, social theory, and the political economy of public health. International Journal of Epidemiology, 33, 650-667.

Tomita, A., \& Burns, J. K. (2013). A multilevel analysis of association between neighborhood social capital and depression: evidence from the first South African National Income Dynamics Study. Journal of Affective Disorders, 144, 101-105.

Yamagishi, T., Cook, K. S., \& Watabe, M. (1998). Uncertainty, trust, and commitment formation in the United States and Japan. American Journal of Sociology, 104, 165-194.

Yamagishi, T., \& Yamagishi, M. (1994). Trust and commitment in the United States and Japan. Motivation and Emotion, 18, 129-166.

Yamazaki, M. (1990). Nihon bunka to kojin shugi [Japanese culture and individualism]. Tokyo: Chuokoron-sha. 
Table 1. Characteristics of study participants $(n=6,416)$

\begin{tabular}{|c|c|c|c|c|}
\hline & & Total & $\begin{array}{l}\text { Men } \\
n=2,771 \\
(43.2 \%)\end{array}$ & $\begin{array}{c}\text { Women } \\
\mathbf{n = 3 , 6 4 5} \\
(\mathbf{5 6 . 8 \%})\end{array}$ \\
\hline Age (years) & & $76.2 \pm 7.1$ & $75.7 \pm 7.0$ & $76.6 \pm 7.2$ \\
\hline Marital status & Unmarried $^{\mathrm{a}}$ & 30.6 & 13.6 & 43.8 \\
\hline Year of residence in the & $1-19$ & 5.7 & 6.2 & 5.3 \\
\hline \multirow[t]{3}{*}{ neighborhood (years) } & $20-39$ & 10.4 & 10.9 & 10.1 \\
\hline & $40-59$ & 36.7 & 17.9 & 51.0 \\
\hline & $60+$ & 47.2 & 65.0 & 33.6 \\
\hline \multirow[t]{5}{*}{ Education } & $\begin{array}{l}\text { Junior high school } \\
\text { graduation }\end{array}$ & 57.1 & 54.7 & 58.9 \\
\hline & High school graduation & 30.5 & 31.3 & 29.9 \\
\hline & $\begin{array}{l}\text { Junior college/vocational } \\
\text { college graduation }\end{array}$ & 6.0 & 3.9 & 7.6 \\
\hline & $\begin{array}{l}\text { College/graduate school } \\
\text { graduation }\end{array}$ & 4.5 & 8.3 & 1.5 \\
\hline & Unknown & 1.9 & 1.7 & 2.1 \\
\hline \multirow{5}{*}{$\begin{array}{l}\text { Annual household income } \\
\text { (millions of yen) }\end{array}$} & $<3.00$ & 49.2 & 49.3 & 49.2 \\
\hline & $3.00-4.99$ & 19.6 & 23.6 & 16.2 \\
\hline & $5.00-6.99$ & 6.7 & 8.0 & 5.6 \\
\hline & $7.00+$ & 4.6 & 5.4 & 3.9 \\
\hline & Unknown & 19.9 & 13.6 & 25.1 \\
\hline Current smoking & & 7.5 & 15.0 & 1.6 \\
\hline \multirow[t]{3}{*}{ Body mass index $\left(\mathrm{kg} / \mathrm{m}^{2}\right)$} & $<18.5$ & 9.0 & 7.8 & 9.9 \\
\hline & $18.5-24.9$ & 67.0 & 69.4 & 65.2 \\
\hline & $25.0+$ & 24.0 & 22.9 & 24.9 \\
\hline \multirow[t]{3}{*}{ Comorbidities } & 0 & 21.8 & 22.7 & 21.1 \\
\hline & 1 & 37.9 & 35.5 & 39.8 \\
\hline & $2+$ & 40.3 & 41.8 & 39.1 \\
\hline Basic activities of daily & Dependent (score of $0-4$ ) & 8.0 & 6.0 & 9.5 \\
\hline \multicolumn{5}{|l|}{ living (range: $0-5$ ) } \\
\hline TMIG-IC (range: 0-13) & & $11.2 \pm 2.7$ & $11.2 \pm 2.6$ & $11.2 \pm 2.7$ \\
\hline Bonding social capital & Weak & 10.5 & 11.5 & 9.8 \\
\hline \multirow[t]{4}{*}{ (homogeneous network) } & Somewhat weak & 7.9 & 9.1 & 7.0 \\
\hline & Neither & 33.0 & 35.8 & 30.7 \\
\hline & Somewhat strong & 31.6 & 30.1 & 32.8 \\
\hline & Strong & 17.0 & 13.5 & 19.7 \\
\hline
\end{tabular}




\begin{tabular}{lllll} 
Bridging social capital & Weak & 20.7 & 18.6 & 22.3 \\
(heterogeneous network) & Somewhat weak & 16.8 & 16.7 & 16.9 \\
& Neither & 44.8 & 46.5 & 43.5 \\
& Somewhat strong & 11.7 & 12.7 & 10.9 \\
& Strong & 6.0 & 5.4 & 6.4 \\
General trust & Weak $^{\mathrm{b}}$ & 54.8 & 49.3 & 59.1 \\
GDS (range: 0-15) & $6+$ & 39.9 & 39.0 & 40.5 \\
\hline
\end{tabular}

GDS: Geriatric Depression Scale. TMIG-IC: Tokyo Metropolitan Institute of Gerontology Index of Competence.

Values are percentages or means \pm standard deviation.

${ }^{a}$ Unmarried includes never married, divorced, and widowed.

${ }^{b}$ Weak consists of the categories of weak, somewhat weak, and neither. Strong consists of the categories of strong and somewhat strong. 
Table 2. Correlations among neighborhood social capital, neighborhood living environment and neighborhood demographics ( $\mathrm{n}=152$ )

\begin{tabular}{|c|c|c|c|c|c|c|c|c|c|c|}
\hline & Mean \pm SD & Min-Max & (a) & (b) & (c) & (d) & (e) & (f) & (g) & (h) \\
\hline \multicolumn{11}{|l|}{ Neighborhood social capital } \\
\hline \multicolumn{11}{|l|}{ (a) Bonding social capital } \\
\hline $\begin{array}{l}\% \text { people who have a strong homogeneous } \\
\text { network in the neighborhood }\end{array}$ & $47.8 \pm 12.1$ & $0.0-80.0$ & 1.00 & -0.05 & 0.11 & $0.27^{* *}$ & 0.06 & $-0.21^{* *}$ & 0.01 & $0.25^{* *}$ \\
\hline \multicolumn{11}{|l|}{ (b) Bridging social capital } \\
\hline $\begin{array}{l}\% \text { people who have a strong heterogeneous } \\
\text { network in the neighborhood }^{\text {a }}\end{array}$ & $19.3 \pm 12.0$ & $0.0-66.7$ & & 1.00 & 0.07 & -0.08 & $-0.29^{* *}$ & $0.31^{* *}$ & $-0.18^{*}$ & 0.05 \\
\hline \multicolumn{11}{|l|}{ (c) General trust } \\
\hline $\begin{array}{l}\% \text { people who have strong general trust in the } \\
\text { neighborhood }^{\text {a }}\end{array}$ & $44.3 \pm 12.5$ & $0.0-100.0$ & & & 1.00 & 0.10 & $0.21^{* *}$ & -0.02 & 0.13 & $-0.31^{* *}$ \\
\hline \multicolumn{11}{|l|}{$\begin{array}{l}\text { Neighborhood living environment } \\
\text { (d) Accessibility to facilities }\end{array}$} \\
\hline $\begin{array}{l}\% \text { people who perceive that there are many } \\
\text { facilities to visit in the neighborhood }{ }^{\mathrm{a}}\end{array}$ & $37.1 \pm 15.4$ & $0.0-100.0$ & & & & 1.00 & 0.09 & 0.06 & 0.06 & -0.02 \\
\hline \multicolumn{11}{|l|}{ (e) Safety } \\
\hline $\begin{array}{l}\% \text { people who perceive that their residential } \\
\text { area is safe in the neighborhood }\end{array}$ & $65.0 \pm 13.8$ & $15.4-100.0$ & & & & & 1.00 & $-0.18^{*}$ & $0.23^{* *}$ & -0.09 \\
\hline \multicolumn{11}{|l|}{ (f) Landscape } \\
\hline $\begin{array}{l}\% \text { people who perceive that there is a great } \\
\text { deal of litter or graffiti in the neighborhood }\end{array}$ & $18.5 \pm 13.0$ & $0.0-80.0$ & & & & & & 1.00 & 0.01 & -0.05 \\
\hline \multicolumn{11}{|l|}{ Neighborhood demographics } \\
\hline (g) Population (people) & $170.1 \pm 122.8$ & $9-633$ & & & & & & & 1.00 & $-0.35^{* *}$ \\
\hline \multicolumn{11}{|l|}{ (h) Aging rate } \\
\hline$\%$ people aged $\geq 65$ years in the neighborhood & $35.5 \pm 11.7$ & $1.7-96.6$ & & & & & & & & 1.00 \\
\hline
\end{tabular}

SD: standard deviation

*** $p<0.01 .{ }^{*} p<0.05$

Correlation coefficients represent Pearson's $r$.

aProportion was calculated from the number of respondents indicating that they "agree" or "somewhat agree" with the statement and the total number of

respondents to each question. 


\begin{tabular}{|c|c|c|c|c|c|c|c|c|c|c|}
\hline & \multicolumn{2}{|c|}{ Model 1} & \multicolumn{2}{|c|}{ Model 2} & \multicolumn{2}{|c|}{ Model 3} & \multicolumn{2}{|c|}{ Model 4} & \multicolumn{2}{|c|}{ Model 5} \\
\hline & OR & $(95 \% \mathrm{CI})$ & OR & $(95 \% \mathrm{CI})$ & OR & $(95 \% \mathrm{CI})$ & OR & $(95 \% \mathrm{CI})$ & OR & $(95 \% \mathrm{CI})$ \\
\hline \multicolumn{11}{|l|}{ Fixed effect } \\
\hline \multicolumn{11}{|l|}{ Individual level } \\
\hline \multicolumn{11}{|l|}{ Bonding social capital } \\
\hline Weak & 1.00 & & & & 1.00 & & 1.00 & & 1.00 & \\
\hline Somewhat weak & 0.76 & $(0.57-1.03)$ & & & 0.85 & $(0.63-1.17)$ & 0.89 & $(0.65-1.22)$ & 0.91 & $(0.66-1.24)$ \\
\hline Neither & 0.68 & $(0.53-0.87)$ & & & 0.82 & $(0.62-1.09)$ & 0.86 & $(0.64-1.15)$ & 0.87 & $(0.65-1.16)$ \\
\hline Somewhat strong & 0.65 & $(0.50-0.85)$ & & & 0.74 & $(0.56-0.98)$ & 0.83 & $(0.62-1.11)$ & 0.81 & $(0.61-1.07)$ \\
\hline Strong & 0.57 & $(0.42-0.77)$ & & & 0.61 & $(0.45-0.82)$ & 0.68 & $(0.50-0.92)$ & 0.67 & $(0.49-0.92)$ \\
\hline \multicolumn{11}{|l|}{ Bridging social capital } \\
\hline Weak & & & 1.00 & & 1.00 & & 1.00 & & 1.00 & \\
\hline Somewhat weak & & & 0.83 & $(0.65-1.05)$ & 0.87 & $(0.68-1.11)$ & 0.86 & $(0.67-1.12)$ & 0.87 & $(0.67-1.13)$ \\
\hline Neither & & & 0.76 & $(0.64-0.90)$ & 0.77 & $(0.63-0.94)$ & 0.77 & $(0.63-0.95)$ & 0.78 & $(0.63-0.96)$ \\
\hline Somewhat strong & & & 0.86 & $(0.68-1.09)$ & 0.90 & $(0.70-1.16)$ & 0.91 & $(0.70-1.19)$ & 0.92 & $(0.71-1.20$ \\
\hline Strong & & & 0.84 & $(0.60-1.19)$ & 0.92 & $(0.64-1.34)$ & 1.05 & $(0.74-1.51)$ & 1.06 & $(0.74-1.52)$ \\
\hline \multicolumn{11}{|l|}{ General trust } \\
\hline Weak & & & & & & & 1.00 & & 1.00 & \\
\hline Strong & & & & & & & 0.54 & $(0.46-0.63)$ & 0.53 & $(0.46-0.62)$ \\
\hline \multicolumn{11}{|l|}{ Neighborhood level $^{\mathrm{a}}$} \\
\hline Bonding social capital & 0.85 & $(0.77-0.94)$ & & & 0.86 & $(0.77-0.95)$ & 0.84 & $(0.75-0.94)$ & 0.85 & $(0.76-0.96)$ \\
\hline Bridging social capital & & & 1.07 & $(0.96-1.21)$ & 1.07 & $(0.95-1.20)$ & 1.07 & $(0.96-1.21)$ & 1.07 & $(0.95-1.20)$ \\
\hline General trust & & & & & & & 1.03 & $(0.92-1.20)$ & 1.09 & $(0.98-1.23)$ \\
\hline \multicolumn{11}{|l|}{ Interaction between individual and neighborhood levels } \\
\hline \multicolumn{11}{|l|}{ Individual bonding social capital by neighborhood bonding social capital } \\
\hline Individual weak $\times$ neighborhood bonding social capital & & & & & & & & & 1.00 & \\
\hline Individual somewhat weak $\times$ neighborhood bonding social capital & & & & & & & & & 1.13 & $(0.78-1.64)$ \\
\hline Individual neither $\times$ neighborhood bonding social capital & & & & & & & & & 1.09 & $(0.81-1.47)$ \\
\hline Individual somewhat strong $\times$ neighborhood bonding social capital & & & & & & & & & 1.55 & $(1.16-2.09)$ \\
\hline Individual strong $\times$ neighborhood bonding social capital & & & & & & & & & 1.40 & $(1.00-2.05)$ \\
\hline
\end{tabular}




\section{Random effect}

Neighborhood level variance (SE)

0.025

(0.013)

$0.035 \quad(0.015)$

$0.023 \quad(0.013)$

0.025

(0.013)

0.027

(0.014)

Intra-class correlation coefficient

0.008 0.011 0.007 0.007 0.008

CI: confidence interval; OR: odds ratio; SE: standard error

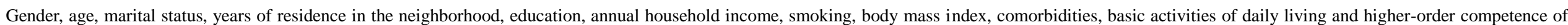
independence at the individual level, and population size and aging rate at the neighborhood level were adjusted for in all models.

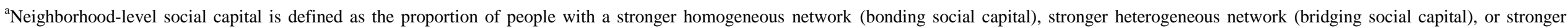
general trust within the neighborhood. ORs associated with a change of one standard deviation in each neighborhood-level social capital are shown. 
Table 4. Associations of bonding and bridging social capital with depressive mood in men: multilevel binomial logistic regression model

\begin{tabular}{|c|c|c|c|c|c|c|c|c|}
\hline & \multicolumn{2}{|c|}{ Model 1} & \multicolumn{2}{|c|}{ Model 2} & \multicolumn{2}{|c|}{ Model 3} & \multicolumn{2}{|c|}{ Model 4} \\
\hline & OR & $(95 \% \mathrm{CI})$ & OR & $(95 \% \mathrm{CI})$ & OR & $(95 \% \mathrm{CI})$ & OR & $(95 \% \mathrm{CI})$ \\
\hline \multicolumn{9}{|l|}{ Fixed effect } \\
\hline \multicolumn{9}{|l|}{ Individual level } \\
\hline \multicolumn{9}{|l|}{ Bonding social capital } \\
\hline Weak & 1.00 & & & & 1.00 & & 1.00 & \\
\hline Somewhat weak & 0.85 & $(0.54-1.34)$ & & & 0.95 & $(0.60-1.52)$ & 1.01 & $(0.64-1.59)$ \\
\hline Neither & 0.69 & $(0.49-0.95)$ & & & 0.85 & $(0.57-1.26)$ & 0.91 & $(0.61-1.36)$ \\
\hline Somewhat strong & 0.61 & $(0.43-0.89)$ & & & 0.72 & (0.48-1.09) & 0.83 & $(0.55-1.25)$ \\
\hline Strong & 0.55 & $(0.36-0.85)$ & & & 0.61 & $(0.40-0.93)$ & 0.68 & $(0.45-1.04)$ \\
\hline \multicolumn{9}{|l|}{ Bridging social capital } \\
\hline Weak & & & 1.00 & & 1.00 & & 1.00 & \\
\hline Somewhat weak & & & 0.78 & $(0.56-1.08)$ & 0.80 & $(0.56-1.15)$ & 0.80 & $(0.56-1.15)$ \\
\hline Neither & & & 0.72 & $(0.55-0.94)$ & 0.74 & $(0.54-1.03)$ & 0.74 & $(0.53-1.03)$ \\
\hline Somewhat strong & & & 0.79 & $(0.57-1.11)$ & 0.86 & $(0.59-1.24)$ & 0.89 & $(0.61-1.29)$ \\
\hline Strong & & & 0.86 & $(0.50-1.47)$ & 0.99 & $(0.57-1.72)$ & 1.17 & $(0.69-1.97)$ \\
\hline \multicolumn{9}{|l|}{ General trust } \\
\hline Weak & & & & & & & 1.00 & \\
\hline Strong & & & & & & & 0.52 & $(0.42-0.64)$ \\
\hline \multicolumn{9}{|l|}{ Neighborhood level $^{\mathrm{a}}$} \\
\hline Bonding social capital & 0.82 & $(0.71-0.94)$ & & & 0.81 & $(0.71-0.94)$ & 0.83 & $(0.72-0.96)$ \\
\hline Bridging social capital & & & 1.02 & $(0.86-1.21)$ & 1.01 & $(0.86-1.19)$ & 0.99 & $(0.84-1.18)$ \\
\hline General trust & & & & & & & 0.94 & $(0.81-1.10)$ \\
\hline \multicolumn{9}{|l|}{ Random effect } \\
\hline Neighborhood level variance (SE) & 0.002 & $(0.002)$ & 0.009 & $(0.008)$ & 0.005 & $(0.005)$ & 0.005 & $(0.006)$ \\
\hline Intra-class correlation coefficient & 0.003 & & 0.001 & & 0.002 & & 1.07 & \\
\hline
\end{tabular}

CI: confidence interval; OR: odds ratio; SE: standard error

Age, marital status, years of residence in the neighborhood, education, annual household income, smoking, body mass index, comorbidities, basic activities of daily living and higher-order competence of independence at the individual level, and population size and aging rate at the neighborhood level were adjusted for in all models.

${ }^{a}$ Neighborhood-level social capital is defined as the proportion of people with a stronger homogeneous network (bonding social capital), stronger heterogeneous network (bridging social capital), or stronger general trust within the neighborhood. ORs associated with a change of one standard deviation in each neighborhood-level social capital are shown. 
Table 4. Associations of bonding and bridging social capital with depressive mood in women: multilevel binomial logistic regression model

\begin{tabular}{|c|c|c|c|c|c|c|c|c|}
\hline & \multicolumn{2}{|c|}{ Model 1} & \multicolumn{2}{|c|}{ Model 2} & \multicolumn{2}{|c|}{ Model 3} & \multicolumn{2}{|c|}{ Model 4} \\
\hline & OR & $(95 \% \mathrm{CI})$ & OR & $(95 \% \mathrm{CI})$ & OR & $(95 \% \mathrm{CI})$ & OR & $(95 \% \mathrm{CI})$ \\
\hline \multicolumn{9}{|l|}{ Fixed effect } \\
\hline \multicolumn{9}{|l|}{ Individual level } \\
\hline \multicolumn{9}{|l|}{ Bonding social capital } \\
\hline Weak & 1.00 & & & & 1.00 & & 1.00 & \\
\hline Somewhat weak & 0.83 & $(0.54-1.27)$ & & & 0.96 & $(0.61-1.49)$ & 1.00 & $(0.64-1.57)$ \\
\hline Neither & 0.73 & $(0.52-1.03)$ & & & 0.88 & $(0.60-1.29)$ & 0.90 & $(0.61-1.33)$ \\
\hline Somewhat strong & 0.75 & $(0.52-1.08)$ & & & 0.86 & $(0.59-1.26)$ & 0.96 & $(0.65-1.41)$ \\
\hline Strong & 0.65 & $(0.44-0.96)$ & & & 0.68 & $(0.46-1.02)$ & 0.78 & $(0.51-1.19)$ \\
\hline \multicolumn{9}{|l|}{ Bridging social capital } \\
\hline Weak & & & 1.00 & & 1.00 & & 1.00 & \\
\hline Somewhat weak & & & 0.92 & $(0.68-1.25)$ & 0.94 & $(0.70-1.28)$ & 0.95 & $(0.69-1.31)$ \\
\hline Neither & & & 0.82 & $(0.65-1.03)$ & 0.81 & $(0.63-1.04)$ & 0.83 & $(0.63-1.08)$ \\
\hline Somewhat strong & & & 0.90 & $(0.65-1.25)$ & 0.89 & $(0.63-1.25)$ & 0.89 & $(0.62-1.28)$ \\
\hline Strong & & & 0.89 & $(0.55-1.43)$ & 0.95 & $(0.57-1.58)$ & 1.06 & $(0.63-1.78)$ \\
\hline \multicolumn{9}{|l|}{ General trust } \\
\hline Weak & & & & & & & 1.00 & \\
\hline Strong & & & & & & & 0.53 & $(0.43-0.66)$ \\
\hline \multicolumn{9}{|l|}{ Neighborhood level $^{\mathrm{a}}$} \\
\hline Bonding social capital & 0.86 & $(0.75-0.99)$ & & & 0.87 & $(0.76-1.01)$ & 0.85 & $(0.72-0.99)$ \\
\hline Bridging social capital & & & 1.13 & $(0.97-1.31)$ & 1.13 & $(0.97-1.32)$ & 1.15 & $(1.00-1.34)$ \\
\hline General trust & & & & & & & 1.09 & $(0.97-1.25)$ \\
\hline \multicolumn{9}{|l|}{ Random effect } \\
\hline Neighborhood level variance (SE) & 0.031 & $(0.015)$ & 0.022 & $(0.012)$ & 0.021 & $(0.012)$ & 0.012 & $(0.009)$ \\
\hline Intra-class correlation coefficient & 0.009 & & 0.007 & & 0.006 & & 0.004 & \\
\hline
\end{tabular}

CI: confidence interval; OR: odds ratio; SE: standard error

Age, marital status, years of residence in the neighborhood, education, annual household income, smoking, body mass index, comorbidities, basic activities of daily living and higher-order competence of independence at the individual level, and population size and aging rate at the neighborhood level were adjusted for in all models.

${ }^{a}$ Neighborhood-level social capital is defined as the proportion of people with a stronger homogeneous network (bonding social capital), stronger heterogeneous network (bridging social capital), or stronger general trust within the neighborhood. ORs associated with a change of one standard deviation in each neighborhood-level social capital are shown. 


\section{Ethics approval}

The study protocol was approved by the Ethical Committee of the Tokyo Metropolitan Institute of Gerontology, Japan. 